Acta Theriologica 40 (3): 257-281, 1995.

PL ISSN 0001-7051

\title{
Group structure and social behaviour of warthogs Phacochoerus aethiopicus
}

\author{
Michael J. SOMERS*, O. Anne E. RASA and Barend L. PENZHORN
}

Somers M. J., Rasa O. A. E. and Penzhorn B. L. 1995. Group structure and social behaviour of warthogs Phacochoerus aethiopicus. Acta Theriologica 40: 257-281.

Data are presented on aspects of the group structure and social behaviour of warthogs Phacochoerus aethiopicus (Pallas, 1767) in the Andries Vosloo Kudu Reserve (AVKR), Eastern Cape Province, South Africa. The social structure of warthogs is one of small groups, usually solitary males or bachelor groups, matriarchal groups consisting of adult females with juveniles and/or yearlings, or yearling groups. Mean group size was 2.21 . Forty five percent of warthogs sighted were solitary. There was a seasonal variation in the mean group size. Differences in social interactions between various age and sex classes are described. Breeding of the warthogs in the AVKR was seasonal with the females coming into oestrus at the end of May and farrowing towards the end of November. The mating system is promiscuous with males roaming during the mating season, mating with numerous females, and females mating with more than one male. Non-offspring nursing occurred.

Centre for Wildlife Management, University of Pretoria, Pretoria, 0002 Republic of South Africa (MJS); Abteilung Ethologie, Zoologisches Institut, Universität Bonn, Kirschallee 1, 53115 Bonn, Germany (OAER); Department of Veterinary Tropical Diseases, Faculty of Veterinary Science, University of Pretoria, Private Bag X04. Onderstepoort, 0110 Republic of South Africa (BLP)

Key words: Phacochoerus aethiopicus, Suidae, social behaviour, group structure, South Africa

\section{Introduction}

Mammalian social systems are complex, and to understand them we need to develop social systems models which incorporate this complexity and yet produce realistic simulations of both the structure at one time and dynamic change through time (Crook et al. 1976). Crook et al. (1976) identified the procedures needed to realize this goal. One procedure given is to identify the principal social system variables which describe the structure of social systems. In this paper we attempt to elucidate two components of this procedure in warthogs Phacochoerus aethiopicus (Pallas, 1767), namely group structure and inter-individual relations. Other components of social systems, ie home range size, range use, dispersal, and

\footnotetext{
* Present address: Department of Zoology, University of Stellenbosch, Private Bag X5018, Stellenbosch, 7599 Republic of South Africa
} 
population structure of the warthogs in this study, have been described elsewhere (Somers and Penzhorn 1992, Somers et al. 1994).

Observations by the second author on a warthog population in Nairobi National Park, Kenya, indicated that social factors may play an important role in regulating populations, especially in areas of high density. Examples of such social regulation mechanisms are non-offspring nursing between sisters and infanticide by mature brothers.

Suids are gregarious, with the social structure generally being that of a family group consisting of females, males and juveniles (Schmidt 1990). A similar social structure to that of the European wild boar Sus scrofa has been reported for warthogs, namely family groups comprising one or more females with juveniles and with or without yearling females (Frädrich 1965, 1974, Bradley 1968, Monfort 1974, Cumming 1975, Rodgers 1977, 1984, Kingdon 1979, Mason 1982, 1990, Radke 1990). The present study is intended to contribute to this understanding and to provide a comparison with the findings of other authors in different geographical areas.

\section{Study site}

The data were collected from the most southerly warthog population, in the Andries Vosloo Kudu Reserve (AVKR) ca $40 \mathrm{~km}$ north-east of Grahamstown, Eastern Cape Province, South Africa, between $33^{\circ} 04^{\prime}$ and $33^{\circ} 09^{\prime} \mathrm{S}$, and $26^{\circ} 37^{\prime}$ and $26^{\circ} 49^{\prime} \mathrm{E}$. The AVKR is 6493 ha in extent and forms part of a larger conservation complex including the Sam Knott Nature Reserve (16551 ha) and the Double Drift Game Reserve (22 994 ha).

According to the Köppen classification of climates, the AVKR rates as $C f a(C$-warm temperate climate, coldest month from $18^{\circ} \mathrm{C}$ to $-3^{\circ} \mathrm{C} ; f$-sufficient precipitation during all months; $a$-maximum temperature over $22^{\circ} \mathrm{C}$ ) (Palmer et al. 1988). Mean annual rainfall is $434 \mathrm{~mm}$, with peaks in October and March (Palmer et al, 1988). Rainfalls for 1988, 1989 and 1990 were 677, 697 and $277 \mathrm{~mm}$ respectively. The vegetation type in which the AVKR is situated, was classified by Acocks (1975) as the Fish River Scrub division of Valley Bushveld. In its undamaged state it is an extremely dense, semi-succulent, thorny scrub, ca $2 \mathrm{~m}$ high; but it has been opened up and overgrazed over large areas (Acocks 1975), A detailed description and classification of the vegetation in the AVKR was given by Palmer (1981).

\section{Methods}

The behavioural data were collected from the central part of the AVKR, most of it being within a $1.5 \mathrm{~km}$ radius of a homestead (Grasslands). The warthogs were habituated to the presence of vehicles, but not humans, before the study began.

Using age estimation criteria based on body and tusk size (Bradley 1972, Mason 1982, 1984) warthogs were assigned to one of four age classes: juveniles - under one year old, yearlings - one to two years old, sub-adults - two to three years old, and adults - three years and older. Following Mason $(1982,1984), 1$ November was assigned as the day on which warthogs would move from one age class to the next.

The age and sex of all warthogs sighted were recorded. Sightings were made around Grasslands homestead and during a $7 \mathrm{~km}$ route travelled ca 3 times per week. A new list of sightings was begun every day and, where possible, repeated sightings of the same group were excluded. Some repeated 
sightings of individuals were unavoidably included as only a limited number could be identified. Almost all the identifiable warthogs were resident near Grasslands homestead.

Group composition was determined and, where possible, relationships and ages of group members estimated. If individuals found together were known not to form a permanent social group they were not recorded as such. With unfamiliar warthogs that could not be observed for long enough to determine whether or not they were a permanent group, they were recorded as such if they were grazing within ca $10 \mathrm{~m}$ of one another.

There were 69 warthog groups sighted which included warthogs which could not be aged. These groups are not included in the data on group structure (see Table 1). Individual warthogs were identified by natural characteristics (ie sex, age, facial configuration, scars and tears in their ears), wherever possible. To distinguish between juveniles, however, artificial marking was necessary, and four individuals (plus one yearling male) were marked by placing holes in their ears. Individuals were given names and codes and sketched and/or photographed to facilitate identification. Thirteen females (coded F1-F13) and 34 males (coded M1-M34) were individually known over the duration of the study period (March $1989-$ December 1990). This information was placed on record cards for easy use in the field.

Most of the observations were conducted from a vehicle. Occasionally observations were made on foot, most of these on an ad lib basis. Groups were observed continually from the time they exited the burrows in the morning to the time they retired in the afternoon or evening. The vehicle was positioned near the group's burrow at dawn or later when it was cold, overcast or raining since the warthogs stayed in their burrows longer under such conditions. The vehicle was moved only when necessary to follow the group on its daily activities. The burrow was observed for $c a 15$ min after their entry in the evening to ensure that they had retired for the night.

Binoculars $(7 \times 35)$ were used when necessary. To determine social interaction rates and type of interaction, scan samples of activities (Altmann 1974) were taken at $5 \mathrm{~min}$ intervals for all visible members of a group. Any behaviour patterns occurring within the $5 \mathrm{~min}$ intervals were also recorded in the sequence in which they occurred. The participants in any social behaviour were recorded as were the results of such behaviour. Suckling frequency and individuals suckled were recorded. The durations of mating and suckling bouts were measured using a stop-watch, as were the time intervals between suckling bouts.

To reduce sampling bias it was proposed to select one group for detailed study over a period of two weeks, after which attention would be concentrated on another group. This was attempted but seldom achieved as the warthogs often disappeared; to maintain a large sample size the next group encountered was studied. During the 1989 mating season, attempts at following a particular group resulted in a reduced number of matings observed compared with the 1990 mating season. In 1990 any warthog which appeared to be courting or was being courted was followed and observed. Though this was not random sampling, it provided important information. At the time of farrowing in 1989 and the time immediately thereafter, observations were concentrated on one female (F1) as she was the only habituated female to raise piglets successfully. In 1990 attention was divided between three females and their progeny. Demographic data were collected on members of focal groups (ie births, deaths, causes of mortality, immigrations, emigrations, etc).

\section{Data analysis}

Differences in social interactions between various age and sex classes were investigated by analysing seven months' data, from 1 November 1989 to 30 May 1990. This period was chosen as the population in the main study area was relatively stable during this time. Data from warthogs F1 (observed for 65.4 h), F2 (31.5 h), F3 (33.8 h), F4 (26.7 h), F5 (20.5 h), F8 (22.6 h), M1 (9.0 h), M5 $(7.4 \mathrm{~h}), \mathrm{M} 13(8.9 \mathrm{~h}), \mathrm{M} 14(10.0 \mathrm{~h}), \mathrm{M} 22(20.5 \mathrm{~h}), \mathrm{M} 28(22.6 \mathrm{~h}), \mathrm{M} 29(22.6 \mathrm{~h})$, and M30 $(22.6 \mathrm{~h})$ were used. Data from the other warthogs were not used as each yielded fewer than five hours of data. These data were collected on an ad lib basis, and some of the warthogs observed were not habituated.

For the statistical analysis the rate of occurrence of each behaviour pattern converted to rate per 10 hours, during each day in which more than 1 hour of data was collected, was determined. The rates 
obtained were then compared between the following classes: adult females (F2, F3, F5), adult males (M5, M13, M14), juveniles (M22, M28, M29, M30, F8), yearling female (F4), and sub-adult female (F1). Since the sample size for young females was small, the results obtained in these cases may reflect individual differences. Only the significant differences are reported.

Matrices giving the mean rates per $10 \mathrm{~h}$ for each of the social behaviours were compiled. As observation times for different individuals and groups differed, matrices show mean rates per 10 hours for each behaviour pattern.

Means are given \pm standard deviations. Mann-Whitney $U$-test (Siegel 1956) was used for statistical analysis, the level of significance being $p=0.05$.

\section{Results}

\section{Group structure}

Forty five percent of warthogs sighted were solitary (Fig. 1). There was a seasonal variation in the mean group size (Fig. 2).
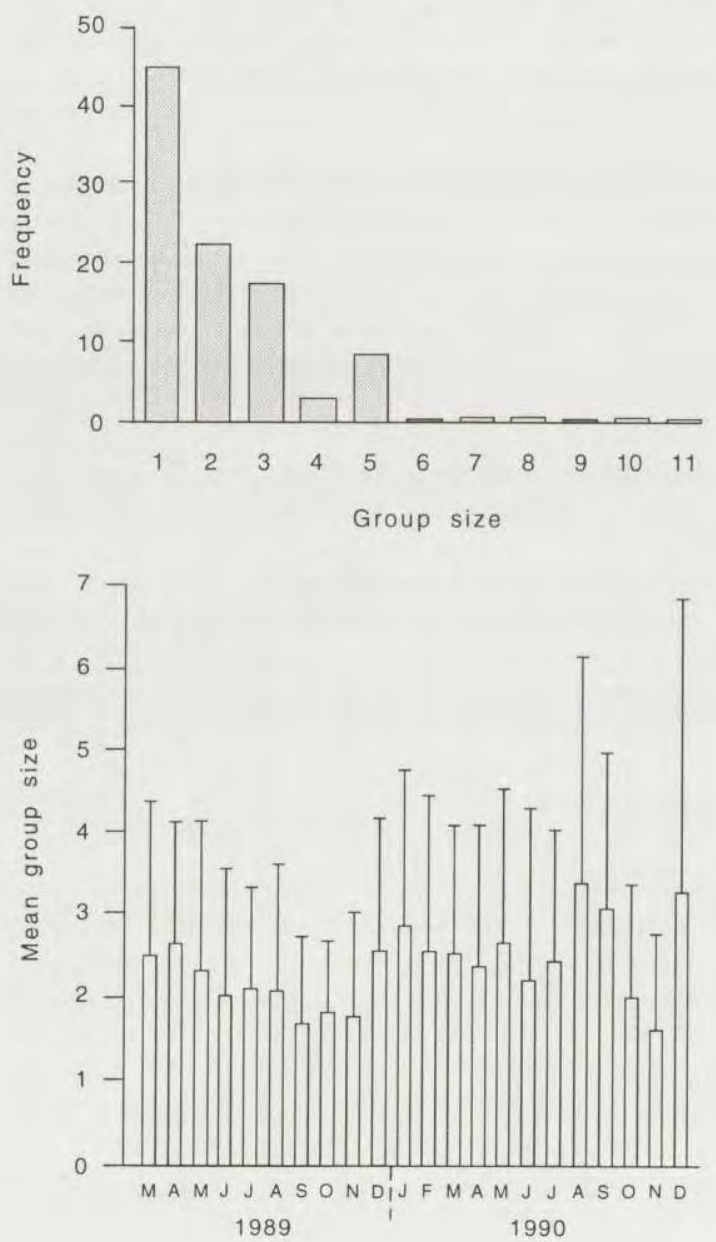

Fig. 1. The percentage frequency distribution of group size classes of warthogs in the Andries Vosloo Kudu Reserve from March 1989 to December 1990 ( $n=910$ sightings).

Fig. 2. The monthly mean group size of warthogs in the Andries Vosloo Kudu Reserve from March 1989 to December 1990. 
The dynamics of the group structure of the warthogs during the study period are given in Figs 3 and 4. The sub-adult and adult females are shown (Fig. 3) to have remained in the study area for longer than the adult males (Fig. 4, see also

Fig. 3. A diagrammatic representation of the dynamics of the structure of the matriarchal warthog groups in the vicinity of Grasslands homestead in the Andries Vosloo Kudu Reserve from March 1989 to December 1990. The lines indicate the structure of groups through time, with boxes showing splitting and coalescing of these groups (A - adult, SA - sub-adult, $\mathrm{Y}$ - yearling, $\mathrm{J}$ - juvenile, $\mathrm{M}$ male, F - female).
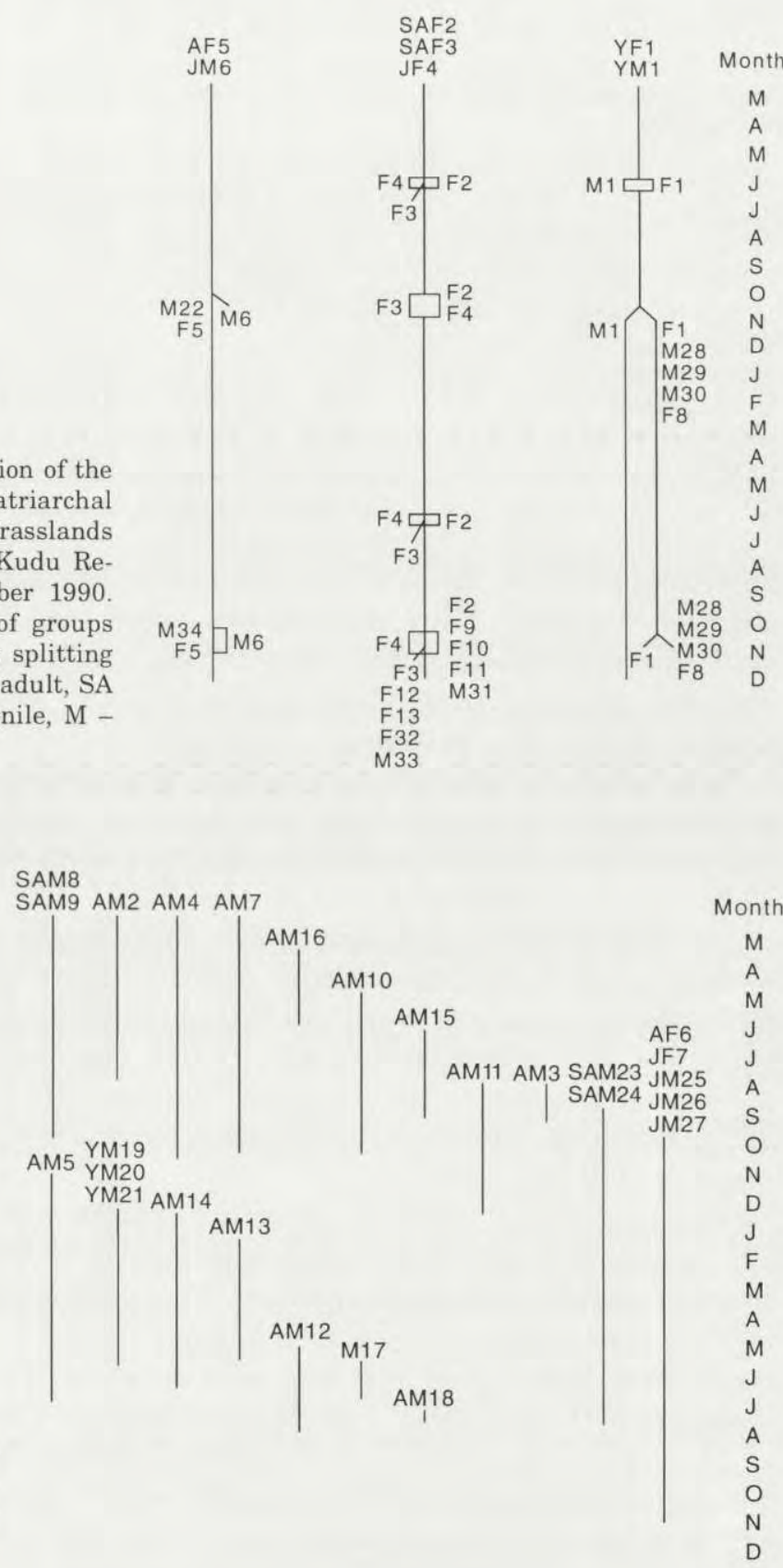

Fig. 4. A diagrammatic representation of the dynamics of the structure of male warthog groups. Denotations as in Fig. 3. 
Table 1. Types and structure of warthog groups in the Andries Vosloo Kudu Reserve sighted between March 1989 and December $1990 . \%$ A, \%Y, \%J - mean percent of adults, yearlings, and juveniles, respectively, within the group type, ${ }^{a}$ family groups comprise one or more adult females with juveniles and with or without yearlings, ${ }^{b}$ other groupings recorded were: $91 \times(1 \mathrm{AF}), 23 \times(1 \mathrm{AF}+1 \mathrm{YF}), 19 \times$ $(2 \mathrm{AF}), 13 \times(1 \mathrm{AF}+1 \mathrm{AM}), 11 \times(1 \mathrm{AF}+1 \mathrm{YM}), 7 \times(2 \mathrm{AF}+1 \mathrm{YF}), 4 \times(2 \mathrm{AF}+1 \mathrm{YM}), 3 \times(1 \mathrm{AF}+2 \mathrm{YF}), 2$ $\times(1 \mathrm{JM}+1 \mathrm{JF}), 2 \times(1 \mathrm{YF}+1 \mathrm{JM}), 2 \times(1 \mathrm{AF}+2 \mathrm{YM}+2 \mathrm{YF}), 2 \times(1 \mathrm{YF}+1 \mathrm{JM}+1 \mathrm{JF}), 2 \times(3 \mathrm{~J}), 1 \mathrm{~J}, 2 \mathrm{~J}$, $3 \mathrm{~J}, 2 \mathrm{JM}, 1 \mathrm{JF}, 2 \mathrm{JF}, 1 \mathrm{AF}+1 \mathrm{Y}, 1 \mathrm{AF}+3 \mathrm{~J}, 1 \mathrm{AF}+2 \mathrm{YF}, 2 \mathrm{AF}+5 \mathrm{Y}, 1 \mathrm{AF}+3 \mathrm{YM}+1 \mathrm{YF}, 1 \mathrm{AM}+1 \mathrm{AF}+\mathrm{JF}$, $1 \mathrm{AM}+1 \mathrm{AF}+2 \mathrm{~J}, 1 \mathrm{AM}-1 \mathrm{AF}+3 \mathrm{~J}, 1 \mathrm{AM}+2 \mathrm{AF}+5 \mathrm{~J}, 1 \mathrm{AM}+2 \mathrm{~J}, 2 \mathrm{AM}+1 \mathrm{JM}, 1 \mathrm{AM}+2 \mathrm{Y}, 1 \mathrm{AM}+1 \mathrm{YF}$, $1 \mathrm{AM}+5 \mathrm{Y}, 1 \mathrm{AM}+1 \mathrm{YM}+1 \mathrm{YF}, 1 \mathrm{AM}+1 \mathrm{~A}, 1 \mathrm{~A}, 4 \mathrm{~A}$. A - adults, $\mathrm{Y}$ - yearlings, J - juveniles, $\mathrm{M}$ - males, $\mathrm{F}$ - females.

\begin{tabular}{|c|c|c|c|c|c|c|c|c|}
\hline \multirow{2}{*}{ Group type } & \multicolumn{2}{|c|}{ Sightings } & \multicolumn{3}{|c|}{ Number of group members } & \multicolumn{3}{|c|}{ Group structure } \\
\hline & $n$ & $\%$ & Mean & SD & Range & $\% \mathrm{~A}$ & $\% \mathrm{Y}$ & $\% J$ \\
\hline Lone adult males & 283 & 31.10 & & & & & & \\
\hline Bachelor groups & 59 & 6.48 & 2.07 & 0.25 & $2-3$ & 95.9 & 4.1 & \\
\hline Family groups ${ }^{a}$ & 235 & 25.82 & 3.99 & 1.72 & $2-11$ & 37.82 & 0.43 & 61.75 \\
\hline Yearling groups & 128 & 14.07 & 2.27 & 1.17 & $1-7$ & & & \\
\hline Other groupings ${ }^{b}$ & 205 & 22.53 & 1.82 & 1.06 & $1-7$ & 65.52 & 23.34 & 11.14 \\
\hline All groupings & 910 & 100.00 & 2.21 & 1.59 & $1-11$ & & & \\
\hline
\end{tabular}

Somers et al. 1994). Groups may fragment in June (mating season) and November (farrowing season). They may coalesce again shortly after these two events.

Four main types of groups were recognised (Table 1), namely lone adult males, bachelor groups, family groups, and yearling groups. All other groups were clumped into "other groupings".

Lone adult males were solitary but occasionally associated with one another or other types of groups when grazing in close proximity to one another. They could also associate with one another for short periods when drinking and/or wallowing at waterholes.

Bachelor groups comprised two or three males of one year old or older. The solitary adult males occasionally formed bachelor groups while grazing together. An example of this was warthogs M1 and M5 which often foraged together during 1990. This was a temporary association as they were often seen alone and retired to separate burrows in the evenings. Warthogs M8 and M9 were a stable bachelor group which remained together permanently, except for the mating season, from March to October 1989.

Yearling groups included any yearling or yearlings without warthogs of other age groups. During 1989 a yearling group consisting of warthogs F1 and M1 was resident near Grasslands homestead. This group broke up for two days during the mating season when M1 was seen alone, while F1 was accompanied by an adult male (M9), with whom she was seen to mate. The two yearlings continued to associate with each other after the two-day disruption.

Matriarchal sounders comprised one or more adult females with juveniles and with or without yearlings. Warthogs F2 and F3 demonstrated that these sounders can be relatively stable for long periods (Fig. 3). They were in the sub-adult class 
with F2 suckling F4 when first encountered in March 1989. These three warthogs were still together at the end of the study period in December 1990. Forty nine percent ( $n=115$ sightings) of the matriarchal groups consisted of two or more adult females.

Other groupings comprised any combination of age and sex not described above. Many of these groups were observed during the mating season owing to stable groups being fragmented and coalescing in transient group structures (see Fig. 3). Of the 91 lone adult females observed (Table 1), 70 (76,9\%) were observed during November and December, which is the approximate time the adult females leave their litters in the burrows and forage alone (see description of offspring care).

\section{Social behaviour}

Resting

Individuals rested together with the other individuals in their respective groups. Matriarchal and yearling groups were never observed resting within sight of other such groups. Adult males occasionally rested within sight of matriarchal and yearling groups. Individuals in temporary and permanent bachelor groups rested together.

\section{Allogrooming}

Allogrooming in the form of rubbing, nibbling and licking was observed. The snout was used to rub or massage other warthogs. Nibbling of the skin and hair on the ventral area with the incisors appeared to be the most common form of allogrooming. On two occasions licking was observed. Rubbing, nibbling and licking occasionally occurred during the same grooming bout. Slight piloerection sometimes occurred during allogrooming. A warthog may "invite" allogrooming by laying down, spreading one or both pairs of limbs and/or rolling over, thus exposing the ventral area. One case of anal licking was observed with F3 licking F2.

The mean rate with which individuals groomed other individuals is given in Fig. 5 and the mean rate with which individuals were groomed by other individuals is given in Fig. 6. A yearling male (M1) was observed grooming an adult male (M4). All other allogrooming occurred between individuals in a group.

Adult females allogroomed significantly more than adult males $(U=-2.902$, $p=0.004$, two-tailed for this and all subsequent Mann-Whitney $U$-tests), juveniles $(U=-2.547, p=0.011)$, and the sub-adult female $(U=-2.082, p=0.037)$. The yearling female allogroomed significantly more than the adult males $(U=-2.923$, $p=0.003)$, juveniles $(U=-2.381, p=0.017)$, and the sub-adult female $(U=-2.036$, $p=0.042$ ).

Adult males were allogroomed significantly less than adult females $(U=2.749$, $p=0.006)$ and the yearling female $(U=2.858, p=0.042)$. 


\begin{tabular}{|l|l|l|l|l|l|l|l|l|l|l|l|l|l|l|}
\hline & F1 & F2 & F3 & F4 & F5 & F8 & M28 & M29 & M30 & M22 & M1 & M5 & M13 & M14 \\
\hline F1 & & & & & & 0.2 & 0.1 & 0.1 & 0.2 & & & & & \\
\hline F2 & & & 1.6 & 1.9 & & & & & & & & & & \\
\hline F3 & & 1.1 & & 0.5 & & & & & & & & & & \\
\hline F4 & & 1.9 & 1.5 & & & & & & & & & & & \\
\hline F5 & & & & & & & & & & 0.5 & & & & \\
\hline F8 & 0.1 & & & & & & & & & & & & & \\
\hline M28 & 0.1 & & & & & 0.2 & & 0.4 & 0.2 & & & & & \\
\hline M29 & 0.1 & & & & & & & & & & & & & \\
\hline M30 & 0.1 & & & & & 0.4 & 0.2 & 0.2 & & & & & & \\
\hline M22 & & & & & 0.5 & & & & & & & & & \\
\hline M1 & & & & & & & & & & & & & & \\
\hline M5 & & & & & & & & & & & & & & \\
\hline M13 & & & & & & & & & & & & & & \\
\hline M14 & & & & & & & & & & & & & & \\
\hline
\end{tabular}

Fig. 5. The mean rate per $10 \mathrm{~h}$ with which each individual groomed every other individual. The numbers indicate the rate per $10 \mathrm{~h}$ of observation of that animal in that row. This explanation applies to all subsequent matrices.

\begin{tabular}{|l|l|l|l|l|l|l|l|l|l|l|l|l|l|l|}
\hline & F1 & F2 & F3 & F4 & F5 & F8 & M28 & M29 & M30 & M22 & M1 & M5 & M13 & M14 \\
\hline F1 & & & & & & 0.1 & 0.1 & 0.2 & 0.1 & & & & & \\
\hline F2 & & & & 1.3 & & & & & & & & & & \\
\hline F3 & & 1.5 & & 1.2 & & & & & & & & & & \\
\hline F4 & & 1.9 & 0.4 & & & & & & & & & & & \\
\hline F5 & & & & & & & & & & 0.5 & & & & \\
\hline F8 & 0.2 & & & & & & & & 0.4 & & & & & \\
\hline M28 & 0.2 & & & & & & & & & & & & & \\
\hline M29 & 0.2 & & & & & & & & 0.2 & & & & & \\
\hline M30 & 0.2 & & & & & 0.2 & 0.2 & 0.2 & & & & & & \\
\hline M22 & & & & & 0.5 & & & & & & & & & \\
\hline M1 & & & & & & & & & & & & & & \\
\hline M5 & & & & & & & & & & & & & & \\
\hline M13 & & & & & & & & & & & & & & \\
\hline M14 & & & & & & & & & & & & & & \\
\hline
\end{tabular}

Fig. 6 . The mean rate per $10 \mathrm{~h}$ with which each individual was groomed by every other individual. 
Play

"Playfighting" was the most common form of playing in the warthogs. Playfighting involved warthogs pushing each other head-on. This may also involve rapid tossing movements of the head. They also hit each other with their heads when in a lateral position. Play occasionally paused momentarily only to continue. Young piglets occasionally bit one another.

Young piglets chased one another in circles, sometimes around an adult, a bush or other piglets. While being chased they occasionally spun rapidly around as much as $360^{\circ}$. Young piglets would usually play on encountering a burrow. They would run in and out of the burrow and then run in circles near the entrance. They tossed small amounts of soil with their snouts.

Social play was occasionally initiated during foraging with two warthogs grazing next to each other. One would nudge the other on the side of the head, the other reacting with a similar nudge. The two would then turn to face each other and begin to play.

The mean rate with which each individual played with every other individual is given in Fig. 7. Adult females played significantly more often than adult males $(U=2.072, p=0.038)$. Juveniles played significantly more often than adult males $(U=-4.566, p<0.001)$, adult females $(U=-3.683, p<0.001)$, the sub-adult female $(U=-4.447, p<0.001)$, and the yearling male $(U=-3.340, p<0.001)$. Adult males also played significantly less often than the yearling female $(U=2.624$, $p=0.008$ ). The yearling female further played significantly more often than the

\begin{tabular}{|l|l|l|l|l|l|l|l|l|l|l|l|l|l|l|}
\hline & F1 & F2 & F3 & F4 & F5 & F8 & M28 & M29 & M30 & M22 & M1 & M5 & M13 & M14 \\
\hline F1 & & & & & & 1.6 & 0.2 & 0.2 & 0.2 & & & & & \\
\hline F2 & & & 2.2 & & & & & & & & & & & \\
\hline F3 & & 1.2 & & 1.2 & & & & & & & & 2.1 & 0.3 & \\
\hline F4 & & 0.4 & 0.7 & & & & & & & & & 1.1 & & \\
\hline F5 & & & & & & & & & & 1.0 & & & & \\
\hline F8 & 1.3 & & & & & & 0.2 & 0.4 & 0.2 & & & & & \\
\hline M28 & 0.4 & & & & & 0.4 & & 0.4 & 0.2 & & & & & \\
\hline M29 & 0.4 & & & & & 0.4 & 0.2 & & 0.2 & & & & & \\
\hline M30 & 0.4 & & & & & 0.2 & 0.2 & 0.2 & & & & & & \\
\hline M22 & & & & & 1.0 & & & & & & & & & \\
\hline M1 & & & & 2.2 & & & & & & & & & & \\
\hline M5 & & & 2.7 & & & & & & & & & & & \\
\hline M13 & & & & 1.1 & & & & & & & 2.2 & & & \\
\hline M14 & & & & & & & & & & & & & & \\
\hline
\end{tabular}

Fig. 7 . The mean rate per $10 \mathrm{~h}$ with which each individual played with every other individual. 
sub-adult male $(U=2.003, p=0.045)$ and the sub-adult female $(U=2.540$, $p=0.011$.

Other observations of adult males' playing, which did not occur during the time of analysis included in Fig. 7, are: adult male M7 approached juvenile female F4 and tried to initiate play by approaching and performing tossing movements with the head in a playful manner. There was no reaction from the juvenile which continued grazing. Adult male M5 was observed playing with juvenile female F4. The initiator of this play was unknown. Juvenile female F4 was observed trying to initiate play with M5 who spun around $180^{\circ}$, in what appeared to be a playful manner, and then resumed grazing. Adult male M4 was also observed having head to head playful fights with yearling male M1. Occasionally M4 would become too aggressive and M1 would squeal and move away.

\section{Greeting}

Greeting involved naso-nasal or naso-oral contacts. Usually one but sometimes both warthogs involved approached the other, which was occasionally a frontal-lateral approach, similar to the threatening stance, but without piloerection. After the initial contact the head was occasionally jerked back before contact was again made. Greeting was followed by playing, fighting or separation of the two warthogs. When juveniles greeted adult males, they usually squealed while approaching in a hesitant manner and then retreated.

The mean rate with which each individual greeted every other individual is given in Fig. 8. Greeting frequently occurred when two groups met, while individual group members greeted after having been separated for short periods. Juveniles were observed greeting juveniles of other groups and also adult males.

\begin{tabular}{|l|l|l|l|l|l|l|l|l|l|l|l|l|l|l|}
\hline & F1 & F2 & F3 & F4 & F5 & F8 & M28 & M29 & M30 & M22 & M1 & M5 & M13 & M14 \\
\hline F1 & & & & & & 0.2 & 0.2 & 0.2 & 0.2 & & & & & \\
\hline F2 & & & & 1.0 & & & & & & & & & & \\
\hline F3 & & 0.3 & & 3.3 & & & & & & & & 0.3 & & \\
\hline F4 & & 0.8 & 4.1 & & & & & & & & & & & \\
\hline F5 & & & & & & & & & & 1.0 & & & & \\
\hline F8 & 0.4 & & & & & & 3.1 & 2.2 & 3.1 & & & & & \\
\hline M28 & 0.4 & & & & & 3.5 & & 2.6 & 2.6 & & & & & \\
\hline M29 & 0.2 & & & & & 1.8 & 2.6 & & 4.0 & & & & & \\
\hline M30 & 0.2 & & & & & 3.5 & 2.2 & 3.5 & & & & & & \\
\hline M22 & & & & & 1.0 & & & & & & & & & \\
\hline M1 & & & & & & & & & & & & & & \\
\hline M5 & & & & 2.7 & & & & & & & & & & \\
\hline M13 & & & & & & & & & & & & & & \\
\hline M14 & & & & & & & & & & & & & & \\
\hline
\end{tabular}

Fig. 8. The mean rate per $10 \mathrm{~h}$ with which each individual greeted every other individual. 
No significant differences were found between the number of times the different classes greeted.

\section{Scent marking}

Object marking was performed by the warthogs rubbing their preorbital and/or oral areas on branches or stems. These two areas correspond to the positions of the preorbital and lip glands (Estes et al. 1982) respectively. The head was moved back and forth one to three times, occasionally using both sides of the face. No sniffing of marks was observed. Marking behaviour never lasted longer than ca 30 seconds.

Defaecation did not appear to be restricted to specific localities. When one member of a group defaecated, others in the group usually followed suit.

During the mating season adult males occasionally urinated by spraying urine over an area of ca $1 \mathrm{~m}^{2}$. On one occasion the area over which a male spray-urinated had just been urinated on by a female. During the mating season adult males were observed to spray-urinate and then scrape soil backwards onto the urine with their forefeet. In one sequence observed, the male spray-urinated, moved backwards, sniffed the ground where he had urinated, then moved forwards again and spray-urinated again before moving off.

Adult females marked objects with a mean rate of 0.18 per 10 hours while adult males marked with a mean rate of 0.1 per 10 hours. There was no significant difference between sexes $(U=0.486, p=0.628)$.

No juveniles or yearlings were observed to mark objects. After warthog F1 became a sub-adult and farrowed, her mean marking rate increased to 0.97 per 10 hours.

Individuals were often observed sniffing objects, but not known marking posts. No unusual response was noticed when warthogs sniffed these objects. On one occasion all three members of a matriarchal group were observed marking the same post with their preorbital region. Only adult males were observed scraping the area in which they had urinated.

Urination may be a form of marking as members within matriarchal groups were observed sniffing urine during and shortly after urination. The frequency of urine marking was not determined. This, however, only occurred during the mating season as did scraping of the ground and own urine. An adult male put his head into a burrow and then urinated at the entrance. No warthogs were present in the burrow at this time, but it was used by a matriarchal group in the evenings.

Allomarking occurred infrequently. Adult females allomarked juveniles with a mean rate of 0.12 per 10 hours. Besides juveniles being allomarked, the only other observations of this were the yearling female (F4) allomarking the two adult females in the group (F2, F3) with a mean rate of 0.3 and 0.8 per 10 hours, respectively. 


\section{Agonistic behaviour}

Agonistic behaviour consisted of anything from a threat to serious and vicious fighting. The process from threat to serious fighting was terminated at any stage by one of the participants.

A threat began with a lateral or frontal-lateral display. Piloerection usually occurred and the tail was lifted and curved around the rump or extended horizontally. The head was also raised. Pawing of the ground was observed in adult males, albeit infrequently. The ears were usually pointed forwards when approaching each other.

The warthogs then approached head-on and sniffed each other in a way similar to greeting, followed by head to head fighting. This involved pushing and occasionally tossing movements of the head. They also stood apart and rushed at each other from a distance of ca 0.5 to $1 \mathrm{~m}$, making contact. The clash of tusks was heard on numerous occasions when adult males had serious fights. The tail was occasionally coiled around the rump or briefly held erect.

On the termination of agonistic behaviour one or both individuals usually left the immediate area. Occasionally they grazed within a few meters of each other, however, ignoring each other.

Submission in the form of retreating and submissive postures was observed. The submissive warthog would lower its head and even go down on its carpals or lie down, pointing its ears backwards. Squealing occasionally occurred. Warthogs retreated by moving away from another after being approached, greeting or

\begin{tabular}{|l|l|l|l|l|l|l|l|l|l|l|l|l|l|l|}
\hline & F1 & F2 & F3 & F4 & F5 & F8 & M28 & M29 & M30 & M22 & M1 & M5 & M13 & M14 \\
\hline F1 & & & 0.2 & & & 0.2 & & & & & & & & \\
\hline F2 & 0.3 & & & & & 0.3 & 0.3 & 0.3 & 0.3 & & & & & \\
\hline F3 & 1.2 & & & 2.4 & & & & & & & 0.9 & & & \\
\hline F4 & 0.8 & & & & & 0.8 & 1.1 & 1.1 & 0.8 & & 0.8 & & & \\
\hline F5 & & & & & & & & & & & & & & \\
\hline F8 & & & & & & & & & & & & & & \\
\hline M28 & & & & & & & & & & & & & & \\
\hline M29 & & & & & & & & & & & & & & \\
\hline M30 & & & & & & & & & & & & & & \\
\hline M22 & & & & & & & & & & & & & & \\
\hline M1 & & & & & & & & & & & & & & \\
\hline M5 & & & & & & & & & & & 5.4 & & & \\
\hline M13 & & & & & & & & & & & & & & \\
\hline M14 & & & & & & & & & & & 2.0 & & & \\
\hline
\end{tabular}

Fig. 9. The mean rate per $10 \mathrm{~h}$ with which each individual attacked every other individual. 
fighting. The retreating warthog occasionally walked backwards for a short distance.

The mean rate with which each individual attacked every other individual is given in Fig. 9, and the mean rate with which each individual was attacked by every other individual is given in Fig. 10. No fighting was observed between adult males outside of the mating season. The sub-adult male (M1), however, was attacked by adult males M5 and M14 (Fig. 9) and adult female F3 (Fig, 10). Although there was no fighting between them adult males did threaten and retreat from one another outside of the mating season (Figs 11 and 12).

Juveniles attacked other classes significantly less often than adult females ( $U$ $=-2.221, p=0.026)$ and adult males $(U=-2.220, p=0.026)$. Adult females were attacked significantly less than the yearling female $(U=2.875, p=0.004)$, the sub-adult male $(U=3.930, p<0.001)$, and the sub-adult female $(U=3.318, p=$ 0.001 ). Adult males were also attacked significantly less than the sub-adult male $(U=2.328, p=0.021)$ and the sub-adult female $(U=1.985, p=0.047)$. The sub-adult male was attacked significantly more often than the juveniles $(U=2.406$, $p=0.016$ )

Juveniles retreated (Fig. 11) significantly less often than the sub-adult male $(U=2.124, p=0.034)$ and the sub-adult female $(U=-2.397, p=0.017)$. The sub-adult female also retreated significantly more often than adult females $(U=$ $2.965, p=0.039$ ). Adult males had other classes retreating from them (Fig. 12) significantly more often than did adult females $(U=-2.277, p=0.023)$ and

\begin{tabular}{|l|l|l|l|l|l|l|l|l|l|l|l|l|l|l|}
\hline & F1 & F2 & F3 & F4 & F5 & F8 & M28 & M29 & M30 & M22 & M1 & M5 & M13 & M14 \\
\hline F1 & & 0.2 & 0.8 & 0.6 & & & & & & & & & & \\
\hline F2 & & & & & & & & & & & & & & \\
\hline F3 & & & & & & & & & & & & & & \\
\hline F4 & & & 3.3 & & & & & & & & & & & \\
\hline F5 & & & & & & & & & & & & & & \\
\hline F8 & & & & & & & & & & & & & & \\
\hline M28 & & & 0.9 & & & & & & & & & & & \\
\hline M29 & & & & & & & & & & & & & & \\
\hline M30 & & & 0.9 & & & & & & & & & & & \\
\hline M22 & & & & & & & & & & & & & & \\
\hline M1 & & & 3.3 & & & & & & & & & & & \\
\hline M5 & & & & & & & & & & & & & & \\
\hline M13 & & & & & & & & & & & & & \\
\hline M14 & & & & & & & & & & & & & & \\
\hline
\end{tabular}

Fig. 10. The mean rate per $10 \mathrm{~h}$ with which each individual was attacked by every other individual. 


\begin{tabular}{|l|l|l|l|l|l|l|l|l|l|l|l|l|l|l|}
\hline & F1 & F2 & F3 & F4 & F5 & F8 & M28 & M29 & M30 & M22 & M1 & M5 & M13 & M14 \\
\hline F1 & & & 0.3 & 0.2 & & & & & & & 0.5 & & & \\
\hline F2 & & & & & & & & & & & & 0.3 & 0.3 & \\
\hline F3 & & & & & & & & & & & & 0.9 & & \\
\hline F4 & & & 0.4 & & & & & & & & & 1.1 & 0.4 & \\
\hline F5 & & & & & & & & & & & 0.5 & & & \\
\hline F8 & & & & & & & & & & & & & & \\
\hline M28 & & & & & & & & & & & & & & \\
\hline M29 & & & & & & & & & & & & & \\
\hline M30 & & & & & & & & & & & & & \\
\hline M22 & & & & & & & & & & & & & \\
\hline M1 & & & & & & & & & & & 2.2 & & \\
\hline M5 & & & & & & & & & & & & & & 2.7 \\
\hline M13 & & & & & & & & & & & & 1.1 & & \\
\hline M14 & & & & & & & & & & & & & \\
\hline
\end{tabular}

Fig. 11. The mean rate per $10 \mathrm{~h}$ with which each individual retreated from every other individual.

\begin{tabular}{|l|l|l|l|l|l|l|l|l|l|l|l|l|l|l|}
\hline & F1 & F2 & F3 & F4 & F5 & F8 & M28 & M29 & M30 & M22 & M1 & M5 & M13 & M14 \\
\hline F1 & & & & & & & & & & & & & & \\
\hline F2 & & & & & & & & & & & & & & \\
\hline F3 & & & & 0.3 & & & & & & & & & & \\
\hline F4 & & & & & & & & & & & & & & \\
\hline F5 & & & & & & & & & & & & & & \\
\hline F8 & & & & & & & & & & & & & & \\
\hline M28 & & & & & & & & & & & & & & \\
\hline M29 & & & & & & & & & & & & & & \\
\hline M30 & & & & & & & & & & & & & & \\
\hline M22 & & & & & & & & & & & & & & \\
\hline M1 & 2.2 & & & & & 2.2 & 2.2 & 2.2 & 2.2 & & & & & \\
\hline M5 & & & & & & & & & & & & & & \\
\hline M13 & & & & & & & & & & & & & & \\
\hline M14 & & 2.0 & 2.0 & 2.0 & & & & & & & 2.0 & 2.0 & 7.0 & \\
\hline
\end{tabular}

Fig. 12. The mean rate per $10 \mathrm{~h}$ of observation with which other individuals retreated from each individual. 
juveniles $(U=-2.486, p=0.013)$. There were no significant differences in how often different classes threatened or were threatened.

Serious and vicious fighting seldom occurred among the warthogs on the AVKR. Three vicious attacks were, however, observed. One was by an adult female towards a juvenile of ca 1.5 months old. The second was directed by adult female F2 at the yearling F4. This attack occurred five days after the adult female lost her young during heavy rains. The third vicious attack was by an unknown female attacking one of the resident females (F5).

Intolerant behaviour usually occurred between matriarchal groups when they met. Vicious attacks were not observed but the sows would occasionally chase the juveniles from the other group for short distances. The only case of infanticide recorded during the study period was from a game guard's report of the ca four-month-old warthog which was "gored by other warthog" (Somers and Penzhorn 1992). Aggression by adult females towards their juveniles was observed to occur from ca 1-2 weeks before they farrowed. This resulted in the juveniles leaving their mothers.

\section{Sexual behaviour}

Breeding of the warthogs in the AVKR was seasonal with the females coming into oestrus at the end of May and farrowing towards the end of November. Gestation was estimated to be 164-182 days, which is similar to that recorded elsewhere (Mason 1982). In 1989 the first behaviour associated with reproduction was observed on 9 May, and the last on 7 June. The first and last matings observed were on 29 May and 6 June respectively. In 1990 the first behaviour associated with reproduction was observed on 10 May, and the last on 3 June. The first and last matings observed were on 30 May and 2 June respectively.

Courtship appeared to be opportunistic. The males would roam and on encountering a female they would first sniff her urine and/or posterior (to determine whether she is in oestrus) and then perhaps continue to court her. Flehmen was not observed.

In 1989 female F1 was observed mating with male M8 on two consecutive days. On the first day warthog M8 continually chased warthog M1 away while he was attempting to court F1. F1 was again courted but not mated by another adult male seven days later. Female F2 was observed being courted by two males on the same day, but mating with one only. The unsuccessful male was animal M10 who had a severe limp and could not keep up with warthog F2 as she moved away. The male M4 was observed mating with F8 and an unknown female two days apart.

In 1990 warthog $\mathrm{F} 1$ was observed mating with three males, M13 and two unknown adult males. While one of the unknown males was mating he dismounted six times to chase another male away which repeatedly approached them from behind. Successful intromission was finally achieved on the severth attempt. M13 was observed mating F1 and F3, and courting F4. M5 mated with warthog F2 and courted F3 and F4.

On one occasion female F4 was being followed by three males. She entered a burrow with one of the nales following her in. This was followed by loud squealing and the male making a rapid exit with warthog F3 also exiting and then chasing him. 
Of the matings observed, $50 \%(n=18)$ involved a second male which was chased away by the male attempting to mate. On all these occasions the male with the female was dominant and mating was eventually successful despite the disturbances. The successful male usually remained with the oestrous female until they retired to different burrows in the evenings.

Other matings of unknown warthogs were observed. No yearling males were observed mating. Yearling male M1 occasionally sniffed the ano-genital region of yearling female F1 during the mating season but never attempted any other form of courtship or mounting. One unknown sub-adult male was observed mating with an unknown yearling female. Although three juveniles were found pregnant during the study period (Somers and Penzhorn 1992), no sexual behaviour was witnessed in juveniles. The mean time of mounting in successful matings was $172.7 \pm 49.3$ $\sec (n=6)$.

One case of a female mounting another female was encountered. This occurred on 8 June 1989 when F3 mounted F2. F3 first put her chin and then her forelimbs on the back of F2 from a lateral and not posterior position. Female F2 did not try to avoid being mounted. The behaviour was preceded and followed by feeding by both animals. The encounter occurred shortly after the females were perceived to have been in oestrus.

\section{Offspring care}

For ca the first two weeks post-partum the piglets remained within the burrows and were suckled there. After the piglets appeared, suckling occurred either while the sow was standing or laying down. Young piglets had to lift their forelimbs off the ground to reach the teats if the sow was standing. Although no data were collected on teat preference, piglets were observed jostling one another while trying to reach the teats. Suckling occurred from either side of the sow. In groups with four juveniles, two usually suckled from either side. Occasionally three would suckle from one side and the fourth from the other side.

When the piglets first exited the burrow they appeared very nervous and continually ran back into the burrow at the slightest disturbance. Once they moved away from the burrow they stayed close to their mother. They soon became more confident and became less attached to their mother. After ca two months the females began weaning the piglets by walking or sitting when they attempted suckling.

In 1989 warthog $\mathrm{F} 1$ farrowed ca $100 \mathrm{~m}$ out of her previous home range (Somers et al. 1994). The date of farrowing was estimated to be 27 or 28 November. Owing to the burrow being in thick bush away from any roads it took five days of following her to find the burrow, as she would move quickly through the bush losing the observer. The juveniles were out for $22 \mathrm{~min}$ on the first outing and 47 min on their second, which occurred on the same day (13 December). No encounters with other groups were observed for the first 16 days after they first exited the burrow.

Female F3 lost her juveniles during heavy rains on 15 and 16 November 1989, when $113 \mathrm{~mm}$ of rain fell within 48 hours. On 17 November she spent almost the entire day walking and running from one burrow to another. On approaching the burrows she started squealing and then attempted to enter them.

The first juveniles in the population were observed on 6 December 1989. In 1990 the first sighting of juveniles was on 19 November. 
The juveniles were reared entirely by the females without any input from the males. The sows did not prevent the juveniles from approaching other warthogs or prevent other warthogs from approaching them. An exception to this was warthogs F2 and F3 which chased the yearling male M1 away every time the two groups met.

Juvenile F4 was last observed suckling from warthog F2 on 5 March 1989, when estimated to be four months old. In 1990 warthog F1 refused her juveniles milk twice on 11 January. One of her teats was, however, red and appeared swollen. Juvenile M29 was refused milk on 13 February 1990 but was again observed suckling on 14 February. This was the last time any of these juveniles were allowed to suckle, when they were ca 10 weeks old.

The mean suckling bout length was $77.5 \pm 24.0 \mathrm{sec}(n=35)$, and the mean interval between suckling bouts was $37.4 \pm 8.9 \mathrm{~min}(n=43)$. No significant difference was found between the suckling bout lengths during first week of observed suckling and the last week of suckling $(U=1.097, p=0.272)$. There were also no significant differences in the time intervals between suckling bouts between the first and last weeks of observed suckling ( $U=-0,386, p=0.699)$.

The exact termination date of F5 suckling M22 was not determined, but suckling had been terminated by 28 February 1990 .

In 1990 warthog F2 farrowed on ca 11 November and brought the juveniles out for the first time on 20 November. The approximate date on which F3 farrowed or the date she first brought her piglets out was not known. On 13 December F2 and F3 rejoined each other with their respective juveniles (Fig. 3). The juveniles of F2 were noticeably smaller than those of F3. On 15 December one of F2's juveniles disappeared and was presumed dead. On the same day sharing of milk was first observed. During one suckling bout two of F3's juveniles suckled from F2. During the following suckling bout one of F2's juveniles suckled from F3. For the first three weeks after rejoining, F2 and F3 allowed each other's juveniles to suckle from them.

F2 injured her left hindlimb in June 1989, which caused her to forage at a slower pace than F3 and F4. The latter two warthogs occasionally moved away leaving F2 (F4's mother) to forage alone, but they always rejoined each other at the burrow in the evenings.

F4 did not produce a litter in 1990 and on 15 December she rejoined her mother (F2) and warthog F3. At first she was hesitant to approach them. Warthogs F2 and F3 reacted seemingly indifferent at her arrival. However, when the group retired for the evening F4 attempted to enter the burrow with them, only to be chased out by F2. No observations were made on 16 November but on 17 November all ten warthogs (F2, F3, F4, and F2's and F3's juveniles) exited from the same burrow and F4 accompanied them permanently thereafter. While all were foraging together warthog F4 always remained close to the juveniles. Occasionally the juveniles accompanied warthog F4 away from the adult females for short periods. The longest recorded separation was $98 \mathrm{~min}$.

Observations on warthog F5 during the 1990 farrowing season were only of short duration. Her progeny of the previous year (M22), however, appeared to have separated from her for ca 1 week during farrowing. They rejoined to form a group of an adult female, a yearling male and a juvenile male.

\section{Discussion}

\section{Group structure}

Group structure changes markedly during the farrowing season. The previous year's juveniles move up to the yearling age class and usually move off to form yearling groups with their siblings, or possibly also with other yearlings. Yearling 
groups of mixed sexes break up as the females farrow. The yearling males then become lone adult males or form a bachelor group with one or two other males.

Cumming (1975) reported a case of two female juveniles of 11 months old remaining together at least until they were five years old. As they were still juveniles when he first captured them, it was presumed that they were siblings. This would support the idea that F2 and F3 were siblings, as they were of the same age class and also formed a stable group for a long time.

Mason (1982) found two to be the most frequent group size class in warthogs while Cumming (1975) found single animals to be the most frequent. Neither authors found a group size class making up more than ca $20 \%$ of the population. The frequency with which solitary warthogs were encountered in the AVKR, therefore, appears unusually high. The mean group size of 2.21 for warthogs in the AVKR is lower than found elsewhere. Mason (1982) reported a mean group size of 3.28. In Nigeria, Henshaw (1975) reported a mean of 3.9 and a range of 1-12. In Tanzania, Rodgers (1977) reported a mean group size of 3.4. Rodgers (1980 cited in Rodgers 1984) recorded a mean of 3.1 and Rodgers (1984) found a mean group size of 3.4 with a trend towards larger group sizes at the time of farrowing. In Cameroon, Esser (1980) recorded a mean of 3.1. Radke (1990) recorded a mean of 2.82 for Masai Mara and 4.57 for Nakuru, Kenya, during 1983 and 1984.

Except for the months of August and September, 1990 the mean group size followed the expected trend, which was that of a sudden increase corresponding to the appearance of the juveniles, and then a gradual decline during the year owing to mortalities. The reason for the apparently unusually high values for August and September 1990 is unknown.

Comparisons between species suggest that food and predation are the main environmental influences on group size (Krebs and Davies 1993). Individuals in groups are less vigilant than solitary individuals (Pulliam 1973) and are also less likely to be predated on owing to the dilution effect (Hamilton 1971, Vine 1971). Group size may be of considerable importance to the animals' survival as Rasa (1986) showed with dwarf mongooses Helogale undulata in the Taru Desert, Kenya, which did not survive in groups of fewer than five individuals. Predation on warthogs in the AVKR during the study period was thought to be minimal (Somers and Penzhorn 1992). This effective lack of predators may, therefore, have allowed the warthogs to form smaller groups than recorded in areas where predators occur.

Most of the larger African ungulates inhabiting open habitats form large groups (Leuthold 1977). Why then do warthogs not form larger groups? The answer may be complex. All the other suids also live in small family groups but generally live in more thickly vegetated areas (Schmidt 1990). As the warthogs' ancestors moved out of the forests into more open area new selective pressures must have been in force. The suids are the only ungulates which regularly bear more than two young per litter (Schmidt 1990). This results in high reproductive rates which may have 
enabled them to withstand high predation pressure, which may be related to their small group sizes. Suids are also generally considered formidable prey, this trait offering them some protection. Larger group sizes may therefore not have been necessary to survive in open habitats. As warthogs are dependent on burrows for protection from the environment, their group size may have evolved as a result of the limitations of burrow size. Larger groups may be prevented by the physical size limitations of burrows.

\section{Social behaviour}

Grooming followed the expected pattern with individuals within groups grooming one another. Grooming between individuals in different groups was rare.

Mason (1982) proposed that playfighting in young warthogs facilitated the development of fighting techniques which may be useful later in life for intra-specific and inter-specific interactions. He also suggested that such contests may determine dominance ranking within litters. The ability to spin around may be helpful in turning to face predators or to turn around quickly to enter a burrow (Bradley 1968). Energy expended in play behaviour does not reduce fitness, but actually increases it (Barber 1991). Playing followed the expected pattern with juveniles playing more frequently than other subgroups.

Scent marking is widespread in mammals (Ralls 1971, Gosling 1985). In warthogs the preorbital and tusk gland follicles are much larger in adult males than in females and sub-adult males (Estes et al. 1982). This suggests that scent marking may be more important in males than in females. As the observations on marking behaviour were not analysed in detail in this study, it is difficult to make any conclusions about the function of marking behaviour. Radke (1985) and Radke and Niemitz (1989), however, in a more detailed study on warthog marking behaviour discussed the function in the social life of warthogs. Both sexes begin marking at six to seven months (Cumming 1975). Unlike the findings in this study, Radke and Niemitz (1989) found marking frequency in males to be significantly higher than in females. This may be due to the lack of present data on marking frequency during the mating season when Cumming (1975) and Radke and Niemitz (1989) found marking frequency in males increased. Radke and Niemitz (1989) also found that during the mating season the males frequently marked the burrows of matriarchal females. They also found marking frequency to increase during agonistic encounters, as did Cumming (1975). Radke and Niemitz (1989) found no correlation between rates of marking and dominance as is widespread in other mammals (Ralls 1971). Males frequently marked the burrows of matriarchal groups, and covered the urine of oestrous females with their own urine. Marking frequency of females was greater on the edges of their home ranges. They concluded that scent marking by females mainly played a role in self orientation, and was not related to territoriality.

Scent marking in juveniles was not observed in the AVKR. Juveniles groomed themselves on objects, however, occasionally rubbing their preorbital area on the objects. Whether this was grooming or scent marking is uncertain. 
Mason (1982) suggested that scent marking, particularly in the vicinity of burrows, could serve as a guide to occupancy of burrows and might even promote "reservation" of burrows for subsequent nights. Cumming (1975) observed warthogs approach already occupied burrows with the intention of entering, only to stop and sniff the ground some paces from the burrow before moving off. Observations in the AVKR indicated that the warthogs, on approaching burrows, did not sniff the ground in a particular way but occasionally sniffed the air before entering or moving away. Although allomarking by and of adult males was not seen, tusk gland secretion may occur during courtship and fighting, but to an unknown extent (Estes et al. 1982). As found by Bradley (1968), Cumming (1975) and Mason (1982) there was no clear evidence that warthogs used defaecation for scent marking.

Range use of the warthogs in the AVKR did not conform to either Wilson's (1975) or Kaufmann's (1983) definitions of territory; they were neither exclusive (Somers et al. 1994) nor defended, nor was there any evidence that dominance relationships changed with location. Territorial behaviour in warthogs has not been reported in any other study and so does not appear to occur in warthogs. Territorial defence is anticipated whenever defence of a specially localised resource is less costly than ignoring other animals in the population and concentrating on efficient exploitation of that resource (Brown 1964). As adult males may spend a considerable amount of energy in defending females during the mating season, defending a territory in addition to this may prove too costly. Social factors such as yearling dispersal and environmental factors may prevent overpopulation of areas. Local resource limitations, which would necessitate individuals defending an area, are therefore not influencing territorial aspects of the social behaviour in warthogs. During dry seasons resources can, however, become limiting for warthogs resulting in heavy mortalities (Mason 1990).

Conflicts between matriarchal groups were suggested by Mason (1982) to be a manifestation of dominance influenced by the spatial proximity of individuals or groups, although not dependent on spatial location. Bradley (1968) also reported that the males with females during the mating season were always dominant to other males regardless of their size. Leuthold (1977) suggested that this was due to a psychological advantage of the possession of a female, similar to the advantage territory holders appear to have over rivals in other species. Radke (1990), however, found an absolute dominance hierarchy in the males and in fights for females the courting male in 'possession' was often defeated and replaced. He also found males being threatened by subordinates, forcing them to dismount and chase the rivals.

The mean rate with which individuals retreated from one another (Figs 11 and 12) show that adult males do meet but withdraw before fighting occurs, with the exception of the sub-adult male which was attacked by other males (Figs 9 and 10). 


\section{Sexual behaviour}

The warthogs in the AVKR were promiscuous, where both males and females mate with more than one partner. An advantage for the female warthogs in being promiscuous, would be to create paternity uncertainty which would prevent males gaining advantage by killing juveniles not considered to be their own (Krebs and Davies 1993). As male warthogs could not guarantee paternity of the offspring of females covered, their promiscuous nature would be an advantage to their fitness, as the more females inseminated the higher the chance of paternity.

The total number of matings which individuals achieved could not be accurately determined as not all of them could be continuously observed during the mating season. The few observations do, however, show some variation in mating success of males. This may be due to female choice. Halliday (1983) stated that as the ratio of male to female parental investment departed from unity, mate choice should be more apparent in the behaviour of the sex investing the most. This would imply that female warthogs should show mate choice. The only male excluded from mating, owing to the females' behaviour, was the warthog with a severe limp (M10). The females' behaviour to run slowly for short distances while being courted may therefore function to exclude males which are not in good physical condition. Physical condition of males may not, however, reflect quality of their genotypes. Halliday (1983) stated that mate choice on the basis of "good genes" was perhaps only tenable where there was evidence that females choose older males, whose ability to survive may have a heritable basis. Except for the exclusion of yearling males, there did not appear to be a choice for older males, though this was not quantitatively determined.

Trivers (1985) proposed that the intensity of competition within a sex depended on how much it invested in parental care. Mating competition should therefore be most intense in the sex which invested less. In warthogs, since males do not contribute to raising young they invest less in parental care. The fighting among males during mating supports Trivers' hypothesis in that mating competition is more intense in males than in females.

During copulation a translucent, gelatinous vaginal plug is deposited in warthogs (Mason 1982). One female which was being accompanied and mated shortly before she was shot, had such a plug. The secretion from the bulbo-urethral glands of male warthogs seems to be the primary source of material for the vaginal plug (Mason 1982). In domestic pigs (Mann 1964) and collared peccaries Tayassu tajacu (Sowls 1966), the postulated function of the vaginal plug was to form a barrier in the cervix and vagina, minimising leakage of the ejaculate back through the vagina, and thereby assisting passage of spermatozoa into the uterus. The plug could lower the chances of subsequent insemination by other males (Mason 1982).

Radke (1990) found evidence that females stimulated competition between males by approaching other males when they were already accompanied by a partner. This was not seen in the warthogs in the present study. 
As pigs have a snout structure which makes inversion of the upper lip impossible they were previously thought not to show flehmen (Dagg and Taub 1970). Dubost (1975) and Martys (1977), however, recorded flehmen in domestic pigs. Radke (1985) using $16 \mathrm{~mm}$ film recognised a slight lift of the males' heads when they sniffed the females' urine and concluded that this was flehmen, though without a marked movement. This was not observed in the warthogs in the AVKR.

\section{Offspring care}

Krebs and Davies (1993) gave four hypotheses for the evolution of co-operation. The one which is thought to apply to warthogs, is that of mutualism where two or more individuals co-operate because each gains a net benefit from doing so. In the case of sows joining and sharing milk there may be an advantage for both sows, and confer benefit on the young (Packer et al. 1992). As shown by a warthog (F2) in this study, a mother may become unfit to forage optimally. The second sow (F3) was able to "replace" the mother and accompany the juvenile (F4). Had the juvenile not been able to forage with another warthog she would have had to forage alone or stay with her mother. The former would have increased her risk of predation and the latter may have caused her to lose condition as did her mother. Creel et al. (1991) found that spontaneous lactating, non-breeding dwarf mongooses who nursed relatives' young, increased their own inclusive fitness by improving the survival of related young. Although warthogs do not lactate spontaneously, the non-offspring nursers may also increase their own inclusive fitness by improving the survival of related young. Joining of groups also increases group size which is considered to lower the risk of predation as discussed above.

As suggested for white-fronted bee-eaters Merops bullockoides (Emlen 1982) and spotted hyaena Crocuta crocuta (Knight et al. 1992) an increase in co-operative breeding, allosuckling in the case of warthogs, may have resulted from decreased rainfall, and the resulting decrease in food (see description of study area).

The help given by the yearling warthog is presumably in the form of guarding of the juveniles. Warthog (F4) always remained close to the juveniles, therefore offering extra protection or at times the only protection for the juveniles.

The strong possibility that warthogs F2 and F3 were full siblings would have benefited F4 as her inclusive fitness would be increased if she increased the survival of F2's and F3's juveniles in 1990, as the coefficient of relatedness between F4 and the juveniles would have been 0.125 to 0.25 . If F2 and F3 were full sisters, as might be the case, the piglets would be 0.25 to 0.5 related to each female, which gives an important genetic advantage to non-offspring nursing.

If females have a greater chance of helping it would pay for the female to produce slightly more females as they can help in rearing the next year's litter. Daughters may therefore give slightly higher return per unit investment. The observation of a male remaining with his mother and younger sibling, however, suggests that it is not just females who help. The inclusive fitness of males is increased through increased survival of their younger siblings. They also have the 
advantage of being with an adult which will increase protection against potential predation.

Social behaviour such as infanticide, observed by the second author in Kenya, was not observed in the AVKR. This may, however, still be a reality in populations where yearlings and sub-adults do not have an area into which they can disperse. Shooting of warthogs in other parts of the AVKR during the study period created such areas.

Acknowledgements: Cape Nature Conservation and Museums is thanked for permission to conduct the research in the AVKR. Thanks for funding goes to the Foundation for Research Development, and the Eugène Marais Chair of Wildlife Management, University of Pretoria. We thank J. A. J. Nel for comments on the manuscript.

\section{References}

Acocks J. P. H. 1975. Veld types of South Africa. Memoirs of the Botanical Survey of South Africa 40: $1-128$.

Altmann J. 1974. Observational study of behavior: sampling methods. Behaviour 49: 227-267.

Barber N. 1991. Play and energy regulation in mammals. Quarterly Review of Biology 66: 129-148.

Bradley R. M. 1968. Some aspects of the ecology of the warthog (Phacochoerus aethiopicus Pallas) in the Nairobi National Park. MSc thesis, University of Nairobi, Nairobi: 1-144.

Bradley R. 1972. A photographic ageing technique used on warthog. East African Wildlife Journal 10: 123-128.

Brown J. L. 1964. The evolution of diversity in avian territorial systems. Wilson Bulletin 76: 160-169.

Creel S. R., Monfort S. L., Wildt D. E. and Waser P. M. 1991. Spontaneous lactation is an adaptive result of pseudopregnancy. Nature, London 351: 660-662.

Crook J. H., Ellis J. E. and Goss-Custard J. D. 1976. Mammalian social systems: Structure and function. Animal Behaviour 24: 261-274.

Cumming D. H. M. 1975. A field study of the ecology and behaviour of warthog. Museum Memoir No 7. National Museums and Monuments of Rhodesia, Salisbury: 1-179.

Dagg A. I. and Taub A. 1970. Flehmen. Mammalia 34: 686-695.

Dubost G. 1975. Le comportement du Chevrotain africain, Hyemoschus aquaticus Ogilby (Artiodactyla, Ruminantia). Zeitschrift für Tierpsychologie 37: 403-501. [In French with English abstract]

Emlen S. T. 1982. The evolution of helping. I. An ecological constraints model. American Naturalist 119: 29-39.

Esser J. D. 1980. Grouping pattern of ungulates in Benoue National Park and adjacent areas, Northern Cameroon. Spixiana 3: 179-191.

Estes R. D., Cumming D. H. M. and Hearn G. W. 1982. New facial glands in domestic pig and warthog. Journal of Mammalogy 63: 618-624.

Frädrich H. 1965. Zur Biologie und Ethologie des Warzenschweines (Phacochoerus aethiopicus Pallas), unter Berücksichtigung des Verhaltens anderer Suiden. Zeitschrift für Tierpsychologie 22: 328-393. [In German with English summary]

Frädrich H. 1974. A comparison of behaviour in the Suidae. [In: The behaviour of ungulates and its relation to management. V. Geist and F. Walther, eds]. International Union for the Conservation of Nature and Natural Resources, Morges: 133-143.

Gosling L. M. 1985. The even-toed ungulates: order Artiodactyla. Sources, behavioural context and function of chemical signals. [In: Social odours in mammals, Vol. 2. R. E. Brown and D. W. Macdonald, eds]. Clarendon Press, Oxford: 550-618.

Halliday T. R. 1983. The study of mate choice. [In: Mate choice. P. Bateson, ed]. Cambridge University Press, Cambridge: $3-32$. 
Hamilton W. D. 1971. Geometry of the selfish herd. Journal of Theoretical Biology 31: 295-311.

Henshaw J. 1975. The ecology and management of Yankari Game Reserve. Technical Report FAO: DP/NIR/72/002, FAO, Rome: 1-106.

Kaufmann J. H. 1983. On the definitions and functions of dominance and territoriality. Biological Reviews 58: 1-20.

Kingdon J. 1979. East African mammals: an atlas of evolution in Africa, Vol. IIIB (large mammals). Academic Press, London: 1-436.

Knight M. H., Van Jaarsveld A. and Mills M. G. L. 1992. Allo-suckling in spotted hyaenas (Crocuta crocuta): an example of behavioral flexibility in carnivores. African Journal of Ecology 30: $245-251$.

Krebs J. R. and Davies N. B. 1993. An introduction to behavioural ecology. Blackwell Scientific Publications, Oxford: 1-420.

Leuthold W. 1977. African ungulates: a comparative review of their ethology and behavioral ecology. Springer-Verlag, Berlin: 1-307.

Mann T. 1964. The biochemistry of semen and of the male reproductive tract. Methuen, London.

Martys M. 1977. Das Flehmen der Schweine Suidae. Zoologische Anzeiger, Jena 199: 43-440. [In German with English abstract]

Mason D. R. 1982. Studies on the biology and ecology of the warthog Phacochoerus aethiopicus sundevalli Lönnberg, 1908 in Zululand. D Sc (Wildlife Management) dissertation, University of Pretoria, Pretoria: $1-326$.

Mason D. R. 1984. Dentition and age determination of the warthog Phacochoerus aethiopicus in Zululand, South Africa. Koedoe 27: 79-119.

Mason D. R. 1990. Juvenile survival and population structure of blue wildebeest and warthogs in the central region of the Kruger National Park during the mid-summer drought of 1988/89. Koedoe 33: $29-45$.

Monfort A. 1974. Quelques aspects de la biologie des phacocheres (Phacochoerus aethiopicus) au Parc National de l'Akagera, Rwanda. Mammalia 38: 177-200. [In French with English summary]

Packer C., Lewis S. and Pusey A. 1992. A comparative analysis of non-offspring nursing. Animal Behaviour 43: 265-281.

Palmer A. R. 1981. A study of the vegetation of the Andries Vosloo Kudu Reserve, Cape Province. M Sc thesis, Rhodes University, Grahamstown: 1-185.

Palmer A. R., Crook B. J. S. and Lubke R. A. 1988. Aspects of vegetation and soil relationships in the Andries Vosloo Kudu Reserve, Cape Province. South African Journal of Botany 54: 309-314.

Pulliam H. R. 1973. On the advantages of flocking. Journal of Theoretical Biology 38: 419-422.

Radke R. 1985. Zur Ökologie und Ethologie des Warzenschweins (P. aethiopicus). Diplomarbeit, Freie Universität Berlin, Berlin: 1-163. [In German with English summary]

Radke R. 1990. Die soziale Organisation des Warzenschweins (Phacochoerus aethiopicus, Pallas). Inaugural-Dissertation zur Erlangung der Doktorwürde, Freie Universität Berlin, Berlin: 1-274. [In German with English summary]

Radke R. and Niemitz C. 1989. Zu Funktionen des Duftdrüsenmarkierens beim Warzenschwein (Phacochoerus aethiopicus). Zeitschrift für Säugetierkunde 54: 111-122. [In German with English abstract]

Ralls K. 1971. Mammalian scent marking. Science 171: 443-449.

Rasa O. A. E. 1986. Ecological factors and their relationships to group size, mortality and behaviour in the dwarf mongoose Helogale undulata (Peters, 1852). Cimbebasia 8(3): 15-21.

Rodgers W. A. 1977. Seasonal change in group size amongst five wild herbivore species. East African Wildlife Journal 15: 175-190.

Rodgers W. A. 1984. Warthog ecology in south east Tanzania. Mammalia 48: 327-350.

Schmidt C. R. 1990. Pigs. [In: Grzimek's Encyclopedia of Mammals, Vol. 3. B. Grzimek, ed]. McGraw-Hill, New York: 20-47.

Siegel S. 1956. Nonparametric statistics for the behavioral sciences. McGraw-Hill, New York: 1-312. 
Somers M. J. and Penzhorn B. L. 1992. Reproduction in a reintroduced warthog population in the eastern Cape Province. South African Journal of Wildlife Research 22: 57-60.

Somers M. J., Penzhorn B. L. and Rasa O. A. E. 1994. Home range size, range use and dispersal of warthogs in the eastern Cape, South Africa. Journal of African Zoology 108: 361-373.

Sowls L. K. 1966. Reproduction in the collared peccary (Tayassu tajacu). Symposia of The Zoological Society of London 15: 155-172.

Trivers R. L. 1985. Social evolution. The Benjamin/Cumming Publishing Company, Menlo Park: $1-462$.

Vine I. 1971. Risk and visual detection and pursuit by a predator and the selective advantage of flocking behaviour. Journal of Theoretical Biology 30: 405-422.

Wilson E. O. 1975. Sociobiology. The new synthesis. Belknap Press of Harvard University Press, Cambridge: $1-697$

Received 1 August 1994, accepted 10 March 1995. 